\title{
Flavonoids, alkaloids and saponins: are these plant-derived compounds an alternative to the treatment of rheumatoid arthritis? A literature review
}

Luis Ângelo Macedo Santiago ${ }^{1}$, Roberval Nascimento Moraes Neto², Ana Caroline Santos Ataíde², Dâmaris Cristina Sousa Carvalho Fonseca ${ }^{3}$, Enio Fernandes Aragão Soares ${ }^{4}$, Joicy Cortez de Sá Sousa ${ }^{3}$, Renata Mondego-Oliveira ${ }^{5}$, Rachel Melo Ribeiro ${ }^{2}$, Maria do Socorro de Sousa Cartágenes ${ }^{2}$, Lídio Gonçalves Lima-Neto ${ }^{3}$, Rafael Cardoso Carvalho ${ }^{2^{*}}$ (i) and Eduardo Martins de Sousa ${ }^{1,2,3}$

\begin{abstract}
Rheumatoid arthritis (RA) is a systemic inflammatory disease characterized by synovial inflammation leading to progressive joint erosion and, eventually, joint deformities. RA treatment includes anti-inflammatories, corticosteroids, synthetic disease-modifying antirheumatic drugs (DMARDs), and immunosuppressants. Drug administration is associated with adverse reactions, as gastrointestinal ulcers, cardiovascular complications, and opportunistic infections. Wherefore, different plant-derived phytochemical compounds are studied like new therapeutic approach to treatment of RA. Among the phytochemical compounds of plants for treatment of RA, flavonoids, alkaloids and saponins are related for present anti-inflammatory activity and act as physiological and metabolic regulators. They have low toxicity compared to other active plant compounds, so their therapeutic properties are widely studied. The intention of the review is to present an overview of the therapeutics of flavonoids, alkaloids, and saponins for RA. An extensive literature survey was undertaken through different online platforms:

PubMed, SciELO, and Virtual Health Library databases, to identify phytochemical compounds used in RA treatment and the descriptors used were medicinal plants, herbal medicines, and rheumatoid arthritis. Seventy-five research and review articles were found to be apt for inclusion into the review. The present study summarizes the phytochemicals isolated from plants that have therapeutic effects on RA models, in vitro and in vivo. The studied substances exerted anti-inflammatory, chondroprotective, immunoregulatory, anti-angiogenic, and antioxidant activities and the most compounds possess good therapeutic properties, valuable for further research for treatment of RA.
\end{abstract}

Keywords: Phytochemical compounds, Flavonoids, Alkaloids, Saponins, Articular disease

\footnotetext{
* Correspondence: carvalho.rafael@ufma.br

${ }^{2}$ Graduate Program in Health Sciences, Federal University of Maranhão -

UFMA, Maranhão, São Luís, Brazil

Full list of author information is available at the end of the article
}

\section{Springer Open}

(c) The Author(s). 2021 Open Access This article is licensed under a Creative Commons Attribution 4.0 International License, which permits use, sharing, adaptation, distribution and reproduction in any medium or format, as long as you give appropriate credit to the original author(s) and the source, provide a link to the Creative Commons licence, and indicate if changes were made. The images or other third party material in this article are included in the article's Creative Commons licence, unless indicated otherwise in a credit line to the material. If material is not included in the article's Creative Commons licence and your intended use is not permitted by statutory regulation or exceeds the permitted use, you will need to obtain permission directly from the copyright holder. To view a copy of this licence, visit http://creativecommons.org/licenses/by/4.0/. 


\section{Introduction}

Rheumatoid arthritis (RA) is a systemic inflammatory disease characterized by symmetrical arthritis and synovial inflammation, progressive joint erosion, and, eventually, joint deformities. It presents autoimmune features and unknown etiology $[1,2]$. The treatment includes anti-inflammatories, corticosteroids, diseasemodifying antirheumatic drugs (DMARDs), and immunosuppressive drugs [3]. Therapeutic drugs used to RA treatment induce many adverse effects such as dermatologic disorders (oral ulcers, alopecia, rash, anaphylactic reactions, photosensitivity, vasculitis and nodulosis), gastrointestinal disturbances (nausea, vomiting, diarrhoea, gastrointestinal bleeding, complication of ulcers), hepatic disease (elevation of liver enzymes, mild and severe fibrosis, cirrhosis), nervous disorders (headache, dizziness, vertigo, fatigue, mood alteration, memory impairment), besides immunosuppression (opportunist infections), serositis (cardiovascular system), osteopathy and renal insufficiency. Due to large number of side effects the use of therapeutic drugs is not always fully effective in RA treatment [3-5].

Phytotherapies that are approved for clinical treatments, which motivates the search for other substances with therapeutic potential for RA, including phytochemicals present in plants [5-7]. Among the phytochemical compounds present in plants, flavonoids, alkaloids and saponins are most related for treatment of RA. They have low toxicity, and their therapeutic properties are widely studied. They are commonly known for their antioxidant properties but have anti-inflammatory effects, inhibiting pro-inflammatory cytokines, proapoptotic effects through the production of caspases, inhibits cartilage and bone destruction, and angiogenesis [8-11]. Flavonoids present antioxidant, antiinflammatory, and immunomodulatory activities [12]. Alkaloids have mainly immunomodulatory action, regulating the cytokines IL-6, IL-12, IL- $1 \alpha$, TNF- $\alpha$, IL-1 $\beta$, and IL-10 [13]. Similarly, saponins also have immunostimulatory properties in RA, mainly in fibroblast-like synoviocytes [14-16].

Thus, the present compilation aimed to highlight an overview of the therapeutic properties of flavonoids, alkaloids, and saponins as potential therapeutic agents for RA.

\section{Methodology}

Substantial literature survey was undertaken to abridge the phytochemical compounds in the treatment of rheumatoid arthritis and its therapeutic properties. We performed a literature review in PubMed, SciELO, and Virtual Health Library databases, to identify medicinal plants used in RA treatment. The descriptors used were medicinal plants, herbal medicines, and rheumatoid arthritis. The acceptability criteria of the included studies were publications about compound phytochemicals isolated from plants that have therapeutic effects on RA models, in vitro and in vivo.

\section{Immunopathology of rheumatoid arthritis}

Although the etiology of RA is not clarified, it is possible to affirm that the disease results from the action of autoreactive $\mathrm{T}$ and $\mathrm{B}$ cells. The cells originate a synovitis process, cell infiltration, bone destruction, and remodeling. Osteoclasts and osteoblast mediate both bone destruction and the remodeling process. During bone erosion, there is an increase in the production of the receptor activator of nuclear factor-kappa-B ligand (RANK L), IL-1, and macrophage colony-stimulating factor (MCSF). Bone damage also occurs through the action of matrix metalloproteinases produced by macrophages, such as MMP9 [17, 18].

$\mathrm{T}$ cells have a role in the pathogenesis of RA, especially Th17 cells. Th17 cells enhance the production of inflammatory cytokines (IL-6, IL-1 $\beta$, and TNF- $\alpha$ ), coordinate bone and cartilage damage [2, 19]. Liu et al. [13] report that high concentrations of TNF- $\alpha$, IL-17, and IL6 are found in collagen-induced arthritis rats, representing the starting point for the inflammatory and immunological process of RA $[20,21]$. It is important to highlight that the inflammatory process in RA involves several cells, including macrophages, fibroblasts, synoviocytes, lymphocytes, chondrocytes, osteocytes, among others [2].

Clinical studies consolidated and validated the major contribution of cytokines to RA pathogenesis [22]. A variety of cytokines appear before the onset of joint disease and throughout the transition from systemic to local disorder [23]. Cytokines are typically secreted by leukocytes and released in the synovial membrane and joint space. Several cytokines of the adaptative immune response are part of the inflammatory process. The joints affected by RA present cell infiltrates composed of $\mathrm{CD}^{+}$and $\mathrm{CD}^{+} \mathrm{T}$ cells, lymphoblasts, plasmocytes, macrophages, and neutrophils, besides pro and antiinflammatory cytokines and chemokines [22-24] .

Prostaglandins and leukotrienes are produced in response to physiological or pathological stimuli, such as synovial membrane injury caused by RA [22]. When the inflammatory process is installed, neutrophils and $\mathrm{CD}^{+} \mathrm{T}$ cells release enzymes, which causes damage to the joint structure [23]. There are three subtypes of T helper lymphocytes, according to the pattern of cytokines they produce. The antigen is presented to naïve $\mathrm{T}$ cells in secondary lymphoid organs, which can differentiate into Th1, Th2, or Th17 cells [25]. The cytokines IL-12 and IFN- $\gamma$ activate Th1 cells, IL4 , IL-5, and IL-13 activate Th2 cells, and TGF- $\beta$ and IL-6 
activate Th17 cells $[22,23,25]$. The main cytokines involved in this process are listed in Table 1.

\section{Phytochemical compounds in the treatment of rheumatoid arthritis}

The number of patients with rheumatoid arthritis increases each year. However, the medications used in the treatment have many side effects. Therefore, there is an intense search for alternative therapies, cheaper, effective, and with fewer side effects [26]. Herbal medicines stand out for their curative effects, and many of them are used for RA clinical treatment [27, 28]. But their efficacy and safety in a long-term clinical application need to be discussed $[29,30]$.

Medicinal plants and their secondary metabolites act in various ways in RA prevention and treatment. Among the components, we highlight the pharmacological effects of flavonoids, alkaloids, and saponins. The effects are related to pain relief, regulation of immune response, cartilage protection, inhibition of synovial hyperplasia, and others [30, 31].

\section{Flavonoids}

There are more than 6,000 flavonoids that act as physiological and metabolic regulators in plants. They present broad action and relatively low toxicity compared to other active plant compounds [12].

Flavonoids are synthesized by the phenylpropanoid metabolic pathway. Along this pathway, flavonoid subgroups with different structural patterns are formed. These structural variations explain the differences observed in the bioactivity of these compounds to the organism [32, 33].
Flavonoids are commonly known for their antioxidant properties; however, they can also exert antiinflammatory effects. They inhibit the production of pro-inflammatory cytokines, nitric oxide (NO), eicosanoids, and interfere with the NF-kB transcription factor [34-37]. The Table 2 describes studies that used flavonoids for RA treatment.

Quercetin is a flavonoid with remarkable properties against RA. When administered orally in rats with collagen-induced arthritis $(150 \mathrm{mg} / \mathrm{mL})$, it decreased the production of IL-17 A and IL-21 [11]. In RAW 264.7 and HIG-82 cells, it decreased TNF- $\alpha$ levels [8]. In a double-blind, randomized controlled trial with 50 women, treated with $500 \mathrm{mg} /$ day for eight weeks, quercetin reduced pain and TNF- $\alpha$ levels [58]. Hesperidin showed protective activity against RA in Wistar rats at a concentration of $50 \mathrm{mg} / \mathrm{kg}$. There was a significant reduction of joint destruction and serum levels of TNF- $\alpha$ when compared to control [59].

The flavonoids baicalin and aglycone (baicalin-2) are found in large amounts in the medicinal plants Scutellaria baicalensis and Oroxylum indicum. They have antiinflammatory and antioxidant activity due to the reduction in reactive oxygen species (ROS) generation, attenuation of NF-kB activity, reduction of cyclooxygenases and TNF- $\alpha$ tumor necrosis factor. For this reason, they are potential targets for RA treatment [9].

Flavonoids from Daphne genkwa, as follows: gentakwanin, hydroxygenkwanin, luteolin, and apigenin, demonstrated anti-inflammatory and immunomodulatory activity. They reduced the expression NO, ROS, TNF- $\alpha$, IL-6, IFN- $\gamma$, and IL-2, which is effective for combating RA $[60,61]$.

Table 1 Cytokines and their role in the immunopathogenesis of Rheumatoid Arthritis

\begin{tabular}{|c|c|c|c|c|}
\hline Cytokine & Producer cells & Target Cell and Effect & $\begin{array}{l}\text { Role in Rheumatoid } \\
\text { Arthritis }\end{array}$ & Reference \\
\hline TNF-a & $\begin{array}{l}\text { Monocytes/ } \\
\text { Macrophages. }\end{array}$ & $\begin{array}{l}\text { Pro-inflammatory action. Differentiation and activation of osteoclasts. } \\
\text { Neovascularization of the endothelium. Inhibition of regulatory T } \\
\text { lymphocytes. }\end{array}$ & Systemic bone erosion & [24] \\
\hline IL-6 & $\begin{array}{l}\text { Monocytes/ } \\
\text { Macrophages. }\end{array}$ & $\begin{array}{l}\text { Macrophage activation and proliferation, with differentiation into } \\
\text { osteoclasts. Multiplication and differentiation of T lymphocytes in the Th17 } \\
\text { subtype. }\end{array}$ & Systemic inflammation & [25] \\
\hline $\mid L-1 a / b$ & $\begin{array}{l}\text { Monocytes/ } \\
\text { Macrophages. }\end{array}$ & Osteoclast activation. T lymphocytes differentiation. Vasodilation. & Pro-inflammatory & [26] \\
\hline IL-17 A & $\begin{array}{l}\text { Th17 } \\
\text { lymphocytes/ } \\
\text { neutrophils }\end{array}$ & $\begin{array}{l}\text { Cell proliferation. IL-6 production. Chondrocyte multiplication. Myeloid cells } \\
\text { and neutrophil chemotaxis. Endothelial neovascularization. }\end{array}$ & Pro-inflammatory & {$[27,28]$} \\
\hline IL-23 & Macrophages & $\begin{array}{l}\text { Development, maintenance, and expansion of Th17 lymphocytes. Induction } \\
\text { of IL-21//L-22 cytokine production. }\end{array}$ & Th17 lymphocytes & [29] \\
\hline IL-21 & $\begin{array}{l}\text { Th17 } \\
\text { lymphocytes/Th2 } \\
\text { cells/NK cells }\end{array}$ & $\begin{array}{l}\text { B cell maturation. Development of plasma cells and production of } \\
\text { antibodies. }\end{array}$ & $\begin{array}{l}\text { Glycosylation of } \\
\text { arthritogenic } \\
\text { autoantibodies }\end{array}$ & [30] \\
\hline IL-12 & Macrophages & Differentiation of Th1 lymphocytes & $\begin{array}{l}\text { Cell-mediated immune } \\
\text { responses, Th17 cell } \\
\text { plasticity }\end{array}$ & [31] \\
\hline
\end{tabular}


Table 2 Phytochemicals used in the treatment of rheumatoid arthritis

\begin{tabular}{|c|c|c|c|c|}
\hline Compound & Chemical structure & Mechanism of action & Effect & References \\
\hline \multicolumn{5}{|l|}{ Flavonoids } \\
\hline Quercetin & & $\begin{array}{l}\text { Decreased expression of IL-17 A, IL-21, and TNF-a. } \\
\text { Decreased migration of Th17 lymphocytes. } \\
\text { Increased expression of IL-10. }\end{array}$ & $\begin{array}{l}\text { Decreased morning pain. } \\
\text { Anti-inflammatory activity. }\end{array}$ & {$[6-8,38]$} \\
\hline Hesperidin & & $\begin{array}{l}\text { Decreased expression of TNF-a. } \\
\text { Decreased osteoclastogenesis. }\end{array}$ & $\begin{array}{l}\text { Anti-inflammatory activity. } \\
\text { Decreased destruction of joint } \\
\text { cartilage. }\end{array}$ & [39] \\
\hline $\begin{array}{l}\text { Baicalin } \\
\text { Aglycone }\end{array}$ & $* *$ & $\begin{array}{l}\text { Decreased ROS and cyclooxygenase production. } \\
\text { Decreased activation of the NFkB signaling pathway. }\end{array}$ & $\begin{array}{l}\text { Anti-inflammatory and } \\
\text { antioxidant activity. }\end{array}$ & [9] \\
\hline $\begin{array}{l}\text { Gentakwanin } \\
\text { Hydroxygenkwanin } \\
\text { Luteolin } \\
\text { Apigenin }\end{array}$ & ** & $\begin{array}{l}\text { Decreased NO and ROS production. } \\
\text { Decreased production of TNF-a, IL-6, INF- }- \text {, and IL-2. }\end{array}$ & $\begin{array}{l}\text { Anti-inflammatory, } \\
\text { immunomodulatory, and } \\
\text { antioxidant activity. }\end{array}$ & {$[40,41]$} \\
\hline Icariin & & $\begin{array}{l}\text { Decrease in osteoclastogenesis markers. } \\
\text { Decrease in Th17 lymphocyte population. }\end{array}$ & $\begin{array}{l}\text { Decreased destruction of } \\
\text { bones and cartilage. } \\
\text { Anti-inflammatory activity. }\end{array}$ & [42] \\
\hline Liquiritin & & $\begin{array}{l}\text { Decreased BCL-2/BAX rate. } \\
\text { JNKI/P38 phosphorylation. }\end{array}$ & $\begin{array}{l}\text { Anti-inflammatory activity. } \\
\text { Angiogenic activity. }\end{array}$ & [43] \\
\hline Oroxylin A & & Decreased rates of IL-1 $\beta$, IL-6, TNF- $\gamma$, and IL-17. & Anti-inflammatory activity & [44] \\
\hline Kaempferol & & $\begin{array}{l}\text { Decreased invasion, proliferation, and invasion of } \\
\text { fibroblast-like synoviocytes. } \\
\text { Decreased production of TNF-a. }\end{array}$ & $\begin{array}{l}\text { Anti-inflammatory activity. } \\
\text { Reduction of cellular infiltrate. }\end{array}$ & {$[45,46]$} \\
\hline
\end{tabular}

Sinomenine

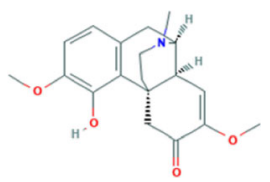

Nicotine
Regulation of IL-6, IL-12, INF- $\gamma$, TNF- $\alpha, \mathrm{IL}-1 \beta$, and II-10. Anti-inflammatory activity.

$[13,47,48]$

Decreased rates of rheumatoid factor, C-reactive protein, Anti-inflammatory activity 
Table 2 Phytochemicals used in the treatment of rheumatoid arthritis (Continued)

Faloxone

\section{Effect}

References

Decreased joint pressure.

[50]

Attenuating RA progression.

Reduces synovial hyperplasia. Anti-inflammatory activity.

Anti-inflammatory activity. Reduction of cartilage degradation.

Anti-inflammatory activity.

Anti-inflammatory and proapoptotic activity.

Decreased proliferation of fibroblast-like synoviocytes. Induction of apoptosis.

Decreased production of IL-6, IL-8, Prostaglandin E2, and NO.

Activation of NFkB signaling pathway.

Inhibits osteoclastogenesis, by inducing the expression of Decreased bone destruction. several genes and markers that lead to osteoclast proliferation.

Anti-inflammatory and proapoptotic activity.

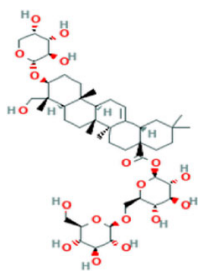

Tubeimoside I

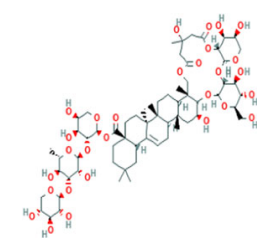

Decreased production of IL-1 $\beta$, IL-6, IL-8, and TNF-a.

Anti-inflammatory activity.

Decreased expression of MMP9.

Attenuation of fibroblast-like synoviocytes phenotypes. 
Table 2 Phytochemicals used in the treatment of rheumatoid arthritis (Continued)

\begin{tabular}{|c|c|c|c|c|}
\hline Compound & Chemical structure & Mechanism of action & Effect & References \\
\hline Pedunculoside & & $\begin{array}{l}\text { Decreased migration and activation of fibroblast-like } \\
\text { synoviocytes. } \\
\text { Decreased production of IL-1 } \beta, I L-6, I L-8 \text {, and TNF-a. } \\
\text { Activation of p38 protein. }\end{array}$ & $\begin{array}{l}\text { Anti-inflammatory and pro- } \\
\text { apoptotic activity. }\end{array}$ & [56] \\
\hline Medecassoside & & $\begin{array}{l}\text { Decreased migration and invasion of fibroblast-like } \\
\text { synoviocytes. } \\
\text { Decreased production of IL-1 } \beta \text {. } \\
\text { Activation of NFkB signaling pathway. }\end{array}$ & $\begin{array}{l}\text { Anti-inflammatory and pro- } \\
\text { apoptotic activity. }\end{array}$ & [57] \\
\hline Hecogenin & & $\begin{array}{l}\text { Decreased migration and invasion of fibroblast-like } \\
\text { synoviocytes. } \\
\text { Induces apoptosis by increasing caspases 3, 8, and } 9 .\end{array}$ & $\begin{array}{l}\text { Anti-inflammatory and pro- } \\
\text { apoptotic activity. }\end{array}$ & \\
\hline Platycodin D & & Decreased production of IL-6 and TNF-a. & Anti-inflammatory activity. & \\
\hline
\end{tabular}

*All chemical structures of the described compounds were obtained on PubChem platform, of the National Library of Medicine (available at: https://pubchem.ncbi.nlm.nih.gov)

${ }^{*}$ Chemical structure formed by more than one phytochemical compound

Icariin, a natural flavonoid isolated from plants of the Epimedium family, decreased bone and cartilage degradation in mice with collagen-induced arthritis. It also inhibited osteoclastogenesis markers in vitro, such as $\beta 3$ integrin, cathepsin $\mathrm{K}$, and MMP9, in addition to decreasing the number of Th17 cells [62].

Liquiritin, a flavonoid extracted from the roots of Glycyrrhiza uralensis, induces synovial membrane apoptosis, promotes DNA fragmentation, changes in the mitochondrial membrane, and decreases the $\mathrm{BCL}-2 / \mathrm{BAX}$ rate, resulting in the reduction of inflammation in collageninduced arthritis in Wistar rats [63].

Another active compound against RA is oroxylin A, a flavonoid known for its anti-inflammatory properties. In an induced RA model in mice, animals treated with oroxylin $\mathrm{A}(10 \mathrm{mg} / \mathrm{mL})$ presented reduced serum levels of IL-1 $\beta$, IL-6, TNF- $\alpha$, and IL-17. Analysis of the T cell population showed an increased number of regulatory $\mathrm{T}$ cells, demonstrating a significant anti-inflammatory activity [38].

Kaempferol inhibits the migration, invasion, and proliferation of fibroblast-like synoviocytes (essential cells in the process of cartilage destruction) and decreases the expression of TNF- $\alpha$. It has a considerable activity against RA, decreasing synovial inflammation and reducing cellular infiltrate $[14,39]$. The roles of flavonoids are summarized in Fig. 1.

\section{Alkaloids}

Alkaloids are a heterogeneous group derived from amino acids with varied biological activities [40, 41] and can be produced by various organisms, such as bacteria, fungi and plants. Here, we will describe studies that used alkaloids in RA treatment. The main points are in Table 2 .

Sinomenime is an alkaloid approved by the Chinese government for RA treatment. It is an anti-inflammatory that regulates the expression of IL-6, IL-12, IL- $1 \alpha$, TNF$\alpha$, IL-1 $\beta$, and IL-10, being a cost-effective alternative to RA treatment [13]. It is also effective when combined with methotrexate, at a dose of $120 \mathrm{mg} /$ day (3:2 proportion). A double-blind study, with 120 patients observed for 24 weeks, demonstrated that the combination resulted in a significant reduction of gastrointestinal side effects [42]. Moreover, sinomenine showed satisfactory results when used through an antioxidant surface thansethosome combined with ascorbic acid, acting on the joint for anti-inflammatory purposes [43].

Nicotine is another active compound in RA treatment. Golbahari and Froushani [44] studied the antiinflammatory effect of nicotine and thymol in Wistar rats with collagen-induced RA. The animals were treated with nicotine orally $(2.5 \mathrm{mg} / \mathrm{kg})$ and showed a significant reduction in the severity of the pathology, as well as decreased rheumatoid factor markers, such as C-reactive 


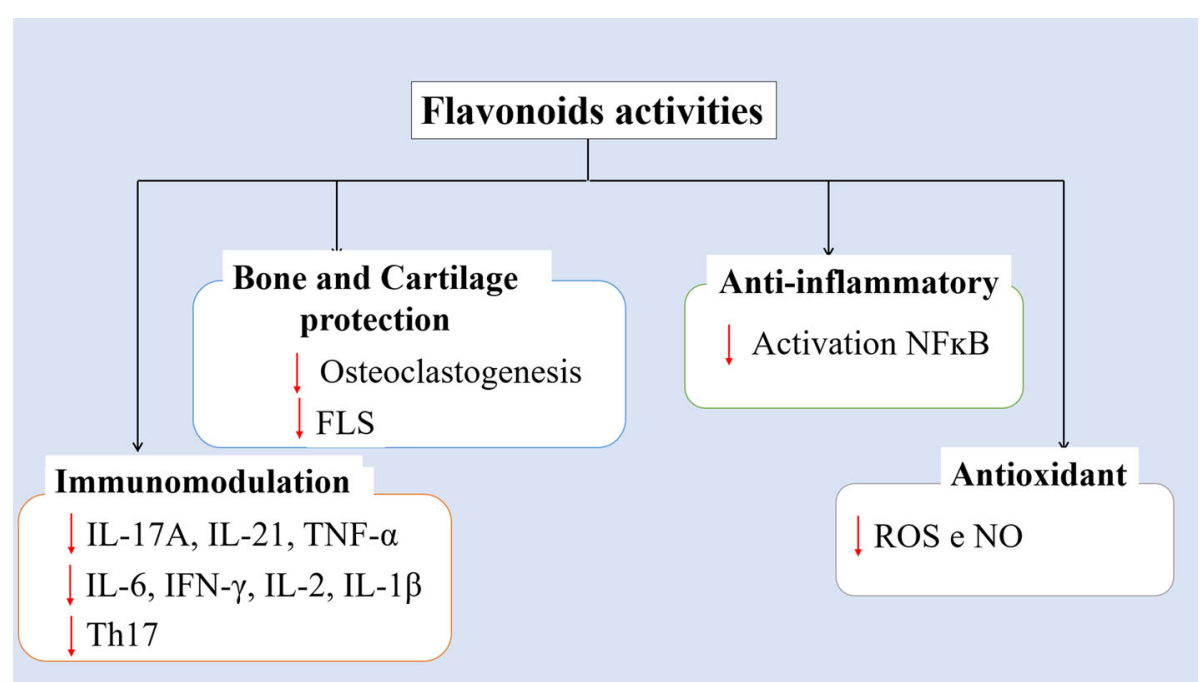

Fig. 1 Biological activities of flavonoids in RA. Legends: FLS- fibroblast-like synoviocytes, NFkB - nuclear factor kB, IL- interleukin, IFN - interferon, TNF - tumor necrosis factor, ROS - reactive oxygen species and NO - nitric oxide

protein, NO, myeloperoxidase, IL- 1, and IL-17. Nicotine, alone or combined with thymol, improved the inflammatory process.

Naloxone is a synthetic alkaloid used as an opioid antagonist. In a double-blind study, patients with RA received a combination of naloxone $(0.2 \mathrm{mg} / \mathrm{mL})$ and morphine $(10 \mathrm{mg} / \mathrm{mL})$ and had a significant decrease in joint pressure [45].

Yang et al. [46] studied the effects of koumine, an alkaloid from Gelsemium elegans, in two experimental RA models in rats, adjuvant-induced arthritis (AIA) and collagen-induced arthritis (CIA). Koumine significantly inhibited RA progression in both models.

Another compound that acts as an adjuvant is berberine. It reduced RA severity in Wistar rats, decreasing IL6 and IL-17 production and increasing the expression of IL-10 and TGF- $\beta$. Moreover, it attenuates synovial hyperplasia and decreases the inflammatory infiltrate in the joint [64].

Fangchinoline significantly reduces the levels of IFN- $\alpha$, IL-6, NO, uric acid and ceruloplasmin, when used in the treatment of rats with collagen-induced RA. It induces chondrocyte proliferation, thus reducing cartilage degeneration [65].

Oxymatrine reduces the expression of IL-6 and IL-8, the migration and invasion of fibroblast-like synoviocytes, and activates the NF-kB signaling pathway. It is potent for joint protection due to its anti-inflammatory response [47]. Ma et al. [48] demonstrated that oxymatrine has the ability to regulate lymphocytes cellular response, decreasing the population of circulating Th17 lymphocytes and increasing the population of regulatory T lymphocytes.
Ellipticine inhibits the proliferation of fibroblast-like synoviocytes in a dose-dependent manner. It also induces cell apoptosis through increased expression of pro-apoptotic genes (caspase-3) and decreased expression of anti-apoptotic genes (Mcl-1, cyclin D1, and $B c l-2)$ [49]. The effects of alkaloids in RA are summarized in Fig. 2.

\section{Saponins}

Saponins are compounds with steroidal or triterpene structures. They possess therapeutic activities related to the diuretic, digestive, antiplasmolytic activity [50]. These are non-protein nitrogen compounds that dissolve in water or foaming solution, thus having the property of emulsifying oils and producing hemolysis [51]. Table 2 lists studies with saponins in RA treatment.

Araloside A, a saponin extracted from the roots of Aralia taibaiensis, inhibited the proliferation of MH7A cells in vitro and decreased the production of IL-6, IL-8, and prostaglandin [10]. This study provided evidence that Araloside A can be a promising therapeutic agent in RA treatment.

Asperosaponin VI inhibits osteoclastogenesis by reducing the expression of genes and markers of signaling pathways that lead to osteoclast proliferation. It protected mice with collagen-induced RA from bone destruction and bone loss [15].

Tubeimoside I is a triterpenoid saponin isolated from Bolbotemma paniculatum. It demonstrated the ability to suppress the production of pro-inflammatory cytokines, such as IL-1 $\beta$, IL-6, IL-8, and TNF- $\alpha$, and decrease the expression of MMP-9 in vitro. In that same study, tubeimoside I was able to attenuate the harmful phenotypes of fibroblast-like synoviocytes in Wistar rats with 


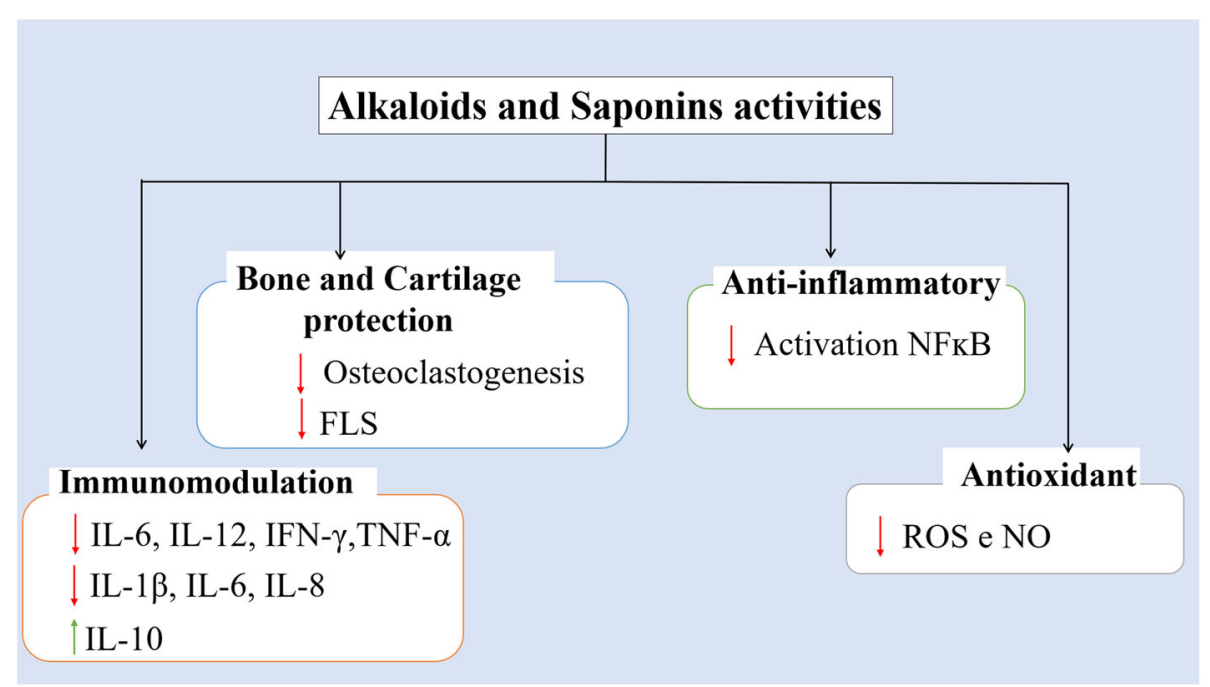

Fig. 2 Biological activities of alkaloids and saponins in RA. Legends: FLS- fibroblast-like synoviocytes, NFkB - nuclear factor kB, IL- interleukin, IFN interferon, TNF - tumor necrosis factor, ROS - reactive oxygen species and NO - nitric oxide

collagen-induced RA, inhibiting cell proliferation and migration. This saponin showed anti-inflammatory activities and is a potential compound for the development of a drug against RA [16].

Pedunculoside is another compound that demonstrated favorable action in Wistar rats with collageninduced RA. It inhibited the proliferation and migration of fibroblast-like synoviocytes and decreased the production of pro-inflammatory cytokines (IL- $1 \beta$, IL-6, IL-8, and TNF- $\alpha$ ). The results suggest that the suppression of TNF- $\alpha$ stimulates the activation of p38 protein, which regulates cell kinase signaling, essential for apoptosis [52].

Madecassoside is a triterpenoid saponin present in Centella asiatica, which has anti-inflammatory activities. It inhibits the migration and invasion of fibroblast-like synoviocytes induced by IL- $1 \beta$ and activates NFkB signaling pathway in adjuvant-induced RA in Wistar rats [53].

Hecogenin is a saponin that demonstrated activities similar to madecassoside. It inhibits the migration of fibroblast-like synoviocytes and stimulating cell apoptosis by increasing the expression of caspases 3,8 , and 9 [66].

Platycodin D is a purified saponin from Platycodi radix. In mice with collagen-induced RAit decreased the production of IL- 6 and TNF- $\alpha$ in a dose-dependent manner [54].

In an experimental model of collagen-induced RA in rats, the total saponins from Rhizoma dioscoreae Nipponicae increase the expression of the vascular endothelial growth factor, angiopoietin, and endothelial tyrosine kinase receptor. These results showed that the saponins inhibits angiogenesis in RA, leading to a better prognosis $[55,67]$. Total saponins from Psammosilene tunicoids also demonstrated activity in combating RA inflammation through downregulation of IL- $1 \beta$ and TNF- $\alpha$. Total saponins of Anemone flacccida Fr. Schmidt inhibit osteoclastogenesis resulting in decreased bone destruction due to collagen-induced RA in Wistar rats $[56,57]$. The effects of alkaloids in RA are summarized in Fig. 2.

\section{Conclusion and future directions}

Conventional RA treatment produces mixed results: some cause undesirable side effects, while others can worsen the disease. Even a low-occurrin g side effect needs to be carefully considered against the drug's therapeutic potential. Conventional drugs that pass the initial tests and are approved for human use may not guarantee complete relief in RA cases.

Flavonoids, alkaloids and saponins from plants can delay or improve RA due to its antioxidant, antiinflammatory, immunomodulatory, and enzymatic effects. These secondaries metabolites can provide abundant chemicals that minimize the disease. Thus, these secondaries metabolites can be promising alternative to the development of therapies capable of improving life quality in patients affected by RA.

In this review, we summarized chemical compounds isolated from plants that have therapeutic effects on RA models in vitro and in vivo. The mechanisms of action of these compounds in RA treatment mainly include anti-inflammatory, immunomodulatory, antioxidant, chondroprotective, and antiangiogenic activities. Most of the compounds possess good drug-like properties, valuable for further research. However, the pharmacological behavior of some compounds needs optimization. 


\section{Acknowledgements}

The authors are thankful to Biodiversity and Biotechnology Network of the Legal Amazon, Graduate Program in Health Sciences - Federal University of Maranhão and Graduate Program in Microbial Biology - CEUMA University for providing all the necessary facilities related to the present work.

\section{Authors' contributions}

EMS and RCC make substantial contribution to conception and design. JCSS, RMO, RMR, MSSC and LGLN participated in the analysis and interpretation of data. LAMS, RNMN, ACSA, DCSCF, EFAS carried out acquisition of data and wrote the paper with input from all authors. All authors read and approved the final manuscript.

\section{Funding}

Not applicable.

\section{Availability of data and materials}

Not applicable.

\section{Declarations}

\section{Ethics approval and consent to participate}

Not applicable.

\section{Consent for publication}

Not applicable.

\section{Competing interests}

There is no conflict of interest.

\section{Author details}

'Biodiversity and Biotechnology Network of the Legal Amazon, University of Maranhão - BIONORTE, State University of Maranhão- UEMA, Maranhão, São Luís, Brazil. ${ }^{2}$ Graduate Program in Health Sciences, Federal University of Maranhão - UFMA, Maranhão, São Luís, Brazil. ${ }^{3}$ Graduate Program in Microbial Biology, CEUMA University - UniCEUMA, Maranhão, São Luís, Brazil. ${ }^{4}$ Santa Terezinha College - CEST, Maranhão, São Luís, Brazil. ${ }^{5}$ Veterinary Medicine Course, Maurício de Nassau College - UNINASSAU, Maranhão, São Luís, Brazil.

\section{Received: 11 January 2021 Accepted: 1 June 2021}

\section{Published online: 24 June 2021}

\section{References}

1. Firestein GS. Evolving concepts of rheumatoid arthritis. Nature. 2003; 423(6937):356-61.

2. Jung SM, Lee J, Baek SY, Lee J, Jang SG, Hong SM, et al. Fraxinellone attenuates rheumatoid inflammation in mice. Int J Mol Sci. 2018:19(3):1-14.

3. Burmester GR, Pope JE. Novel treatment strategies in rheumatoid arthritis. Lancet. 2017;389(10086):2338-48. Available from: https://doi.org/10.1016/ S0140-6736(17)31491-5.

4. K. A, U. M-L. Side effects and management of side effects of methotrexate in rheumatoid arthritis. Clin Exp Rheumatol. 2010;28(5 SUPPL. 61):S95-101. Available from: https://www.clinexprheumatol.org/article.asp?a=4095\%0A http://ovidsp.ovid.com/ovidweb.cgi?T=JS\&PAGE=reference\&D = emed9\&NEWS=N\&AN=2010707610

5. Narváez J. Tratamiento de la artritis reumatoide. Med Clin (Barc). 2016;147(4): 176-80. Available from: https://doi.org/10.1016/j.medcli.2016.03.005.

6. Haleagrahara N, Miranda-Hernandez S, Alim MA, Hayes L, Bird G, Ketheesan $\mathrm{N}$. Therapeutic effect of quercetin in collagen-induced arthritis. Biomed Pharmacother. 2017;90:38-46. Available from: https://doi.org/10.1016/j. biopha.2017.03.026.

7. Piovezana Bossolani GD, Silva BT, Colombo Martins Perles JV, Lima MM, Vieira Frez FC, Garcia de Souza SR, et al. Rheumatoid arthritis induces enteric neurodegeneration and jejunal inflammation, and quercetin promotes neuroprotective and anti-inflammatory actions. Life Sci. 2019;238: 116956. Available from: https://doi.org/10.1016/j.lfs.2019.116956. Elsevier Inc.

8. Gokhale JP, Mahajan HS, Surana SS. Quercetin loaded nanoemulsion-based gel for rheumatoid arthritis: In vivo and in vitro studies. Biomed Pharmacother. 2019;112(July 2018):108622. Available from: https://doi.org/1 0.1016/j.biopha.2019.108622.
9. Dinda B, Dinda S, DasSharma S, Banik R, Chakraborty A, Dinda M. Therapeutic potentials of baicalin and its aglycone, baicalein against inflammatory disorders. Eur J Med Chem. 2017;131:68-80. Available from: https://doi.org/10.1016/j.ejmech.2017.03.004.

10. Ding $Y$, Zhao Q, Wang L. Pro-apoptotic and anti-inflammatory effects of araloside A on human rheumatoid arthritis fibroblast-like synoviocytes. Chem Biol Interact. 2019;306(115):131-7.

11. Yang $Y$, Zhang X, Xu M, Wu X, Zhao F, Zhao C. Quercetin attenuates collagen-induced arthritis by restoration of Th17/Treg balance and activation of Heme Oxygenase 1-mediated anti-inflammatory effect. Int Immunopharmacol. 2018;54(June 2017):153-62. Available from: https://doi. org/10.1016/j.intimp.2017.11.013.

12. Serafini M, Peluso I, Raguzzini A. Flavonoids as anti-inflammatory agents Proc Nutr Soc. 2010;69(3):273-8.

13. Liu W, Zhang Y, Zhu W, Ma C, Ruan J, Long H, et al. Sinomenine Inhibits the Progression of Rheumatoid Arthritis by Regulating the Secretion of Inflammatory Cytokines and Monocyte/Macrophage Subsets. Front Immunol. 2018;9(September):2228.

14. Lee CJ, Moon SJ, Jeong JH, Lee S, Lee MH, Yoo SM, et al. Kaempferol targeting on the fibroblast growth factor receptor 3-ribosomal S6 kinase 2 signaling axis prevents the development of rheumatoid arthritis. Cell Death Dis. 2018;9(3). Available from: https://doi.org/10.1038/s41419-018-0433-0.

15. Liu K, Liu Y, Xu Y, Nandakumar KS, Tan H, He C, et al. Asperosaponin VI protects against bone destructions in collagen induced arthritis by inhibiting osteoclastogenesis. Phytomedicine. 2019;63(April):153006. Available from: https://doi.org/10.1016/j.phymed.2019.153006.

16. Liu Z, Zhou L, Ma X, Sun S, Qiu H, Li H, et al. Inhibitory effects of tubeimoside I on synoviocytes and collagen-induced arthritis in rats. J Cell Physiol. 2018;233(11):8740-53.

17. Yap H-Y, Tee S, Wong M, Chow S-K, Peh S-C, Teow S-Y. Pathogenic Role of Immune Cells in Rheumatoid Arthritis: Implications in Clinical Treatment and Biomarker Development. Cells. 2018:7(10):161.

18. Firestein GS, McInnes IB. Immunopathogenesis of Rheumatoid Arthritis Immunity. 2017:46(2):183-96.

19. Wang N, Zhao X, Huai J, Li Y, Cheng C, Bi K, et al. Arachidonic acid metabonomics study for understanding therapeutic mechanism of Huo Luo Xiao Ling Dan on rat model of rheumatoid arthritis. J Ethnopharmacol. 2018;217:205-11. Available from: https://doi.org/10.1016/j.jep.2018.02.027.

20. Liu W, Sun Y, Cheng Z, Guo Y, Liu P, Wen Y. Crocin exerts anti-inflammatory and anti-arthritic effects on type II collagen-induced arthritis in rats. Pharm Biol. 2018;56(1):209-16. Available from: https://doi.org/10.1080/13880209.201 8.1448874 .

21. Abed El-Gaphar OAM, Abo-Youssef AM, Halal GK. Levetiracetam mitigates lipopolysaccharide-induced JAK2/STAT3 and TLR4/MAPK signaling pathways activation in a rat model of adjuvant- induced arthritis. Eur J Pharmacol. 2018;826:85-95. Available from: https://doi.org/10.1016/j.ejphar.2018.02.041.

22. Mclnnes IB, Buckley CD, Isaacs JD. Cytokines in rheumatoid arthritis-shaping the immunological landscape. Nat Rev Rheumatol. 2016;12(1):63-8. Available from: https://doi.org/10.1038/nrrheum.2015.171.

23. Ridgley LA, Anderson AE, Pratt AG. What are the dominant cytokines in early rheumatoid arthritis? Curr Opin Rheumatol. 2018:30(2):207-14

24. Crowley T, O'Neil JD, Adams H, Thomas AM, Filer A, Buckley CD, et al. Priming in response to pro-inflammatory cytokines is a feature of adult synovial but not dermal fibroblasts. Arthritis Res Ther. 2017;19(1):1-11.

25. Tanaka T, Narazaki M, Kishimoto T. II-6 in inflammation, Immunity, And disease. Cold Spring Harb Perspect Biol. 2014;6(10):1-16.

26. Aletaha D, Smolen JS. Diagnosis and Management of Rheumatoid Arthritis: A Review. J Am Med Assoc. 2018;320(13):1360-72

27. Luo $C$, Xu X, Wei $X$, Feng W, Huang H, Liu H, et al. Natural medicines for the treatment of fatigue: Bioactive components, pharmacology, and mechanisms. Pharmacol Res. 2019;148(August):104409. Available from: https://doi.org/10.1016/j.phrs.2019.104409.

28. Newman DJ, Cragg GM. Natural Products as Sources of New Drugs from 1981 to 2014. J Nat Prod. 2016;79(3):629-61.

29. Pu J, Fang FF, Li XQ, Shu ZH, Jiang YP, Han T, et al. Matrine exerts a strong anti-arthritic effect on type II collagen-induced arthritis in rats by inhibiting inflammatory responses. Int J Mol Sci. 2016;17(9):1-13.

30. Zhang Q, Peng W, Wei S, Wei D, Li R, Liu J, et al. Guizhi-Shaoyao-Zhimu decoction possesses anti-arthritic effects on type II collagen-induced arthritis in rats via suppression of inflammatory reactions, inhibition of invasion \& migration and induction of apoptosis in synovial fibroblasts. 
Biomed Pharmacother. 2019;118(August):109367. Available from: https://doi. org/10.1016/j.biopha.2019.109367.

31. Soeken KL, Miller SA, Ernst E. Herbal medicines for the treatment of rheumatoid arthritis: A systematic review. Rheumatology. 2003:42(5):652-9.

32. De Villiers $A$, Venter $P$, Pasch $H$. Recent advances and trends in the liquidchromatography-mass spectrometry analysis of flavonoids. J Chromatogr A. 2015;1430:16-78. Available from: https://doi.org/10.1016/j.chroma.2015.11.077.

33. Jackson JK, Higo T, Hunter WL, Burt HM. The antioxidants curcumin and quercetin inhibit inflammatory processes associated with arthritis. Inflamm Res. 2006;55(4):168-75.

34. Burda S, Oleszek W. Antioxidant and antiradical activities of flavonoids. J Agric Food Chem. 2001:49(6):2774-9.

35. Cao G, Sofic E, Prior RL. Antioxidant and prooxidant behavior of flavonoids: Structure-activity relationships. Free Radic Biol Med. 1997;22(5):749-60.

36. Li AN, Li S, Zhang YJ, Xu XR, Chen YM, Li H, Bin. Resources and biological activities of natural polyphenols. Nutrients. 2014;6(12):6020-47.

37. Saija A, Scalese M, Lanza M, Marzullo D, Bonina F, Castelli F. Flavonoids as antioxidant agents: Importance of their interaction with biomembranes. Free Radic Biol Med. 1995;19(4):481-6.

38. Wang Y, Gao J, Xing LZ. Therapeutic potential of Oroxylin A in rheumatoid arthritis. Int Immunopharmacol. 2016;40:294-9. Available from: https://doi. org/10.1016/j.intimp.2016.09.006.

39. Pan D, Li N, Liu Y, Xu Q, Liu Q, You Y, et al. Kaempferol inhibits the migration and invasion of rheumatoid arthritis fibroblast-like synoviocytes by blocking activation of the MAPK pathway. Int Immunopharmacol. 2018; 55(August 2017):174-82. Available from: https://doi.org/10.1016/j.intimp.201 7.12.011.

40. Boratyński PJ, Zielińska-Błajet M, Skarżewski J. Cinchona Alkaloids-Derivatives and Applications. Alkaloids Chem Biol. 2019;82:29145.

41. Liu C, Yang S, Wang K, Bao X, Liu Y, Zhou S, et al. Alkaloids from Traditional Chinese Medicine against hepatocellular carcinoma. Biomed Pharmacother. 2019;120(October):109543. Available from: https://doi.org/10.1016/j.biopha.2 019.109543.

42. Huang R, Pan H, dan, Wu J, Zhou H, Li Z, guo, Qiu P, et al. Comparison of combination therapy with methotrexate and sinomenine or leflunomide for active rheumatoid arthritis: A randomized controlled clinical trial. Phytomedicine. 2019;57(October 2018):403-10. Available from: https://doi. org/10.1016/j.phymed.2018.12.030.

43. Song $\mathrm{H}$, Wen J, Li H, Meng Y, Zhang $\mathrm{Y}$, Zhang $\mathrm{N}$, et al. Enhanced transdermal permeability and drug deposition of rheumatoid arthritis via sinomenine hydrochloride-loaded antioxidant surface transethosome. Int $J$ Nanomedicine. 2019;14:3177-88.

44. Golbahari S, Abtahi Froushani SM. Synergistic benefits of Nicotine and Thymol in alleviating experimental rheumatoid arthritis. Life Sci. 2019;239: 117037. Available from: https://doi.org/10.1016/j.lfs.2019.117037.

45. Palareti G, Legnani C, Cosmi B, Antonucci E, Erba N, Poli D, et al. Comparison between different D-Dimer cutoff values to assess the individual risk of recurrent venous thromboembolism: Analysis of results obtained in the DULCIS study. Int J Lab Hematol. 2016;38(1):42-9.

46. Yang J, Cai H, Da, Zeng YL, Chen ZH, Fang MH, Su YP, et al. Effects of Koumine on Adjuvant- and Collagen-Induced Arthritis in Rats. J Nat Prod. 2016;79(10):2635-43.

47. Liang J, Chang B, Huang M, Huang W, Ma W, Liu Y, et al. Oxymatrine prevents synovial inflammation and migration via blocking NF-KB activation in rheumatoid fibroblast-like synoviocytes. Int Immunopharmacol. 2018; 55(October 2017):105-11. Available from: https://doi.org/10.1016/j.intimp.2 017.12.006.

48. Ma A, Yang Y, Wang $Q$, Wang $Y$, Wen J, Zhang Y. Anti-inflammatory effects of oxymatrine on rheumatoid arthritis in rats via regulating the imbalance between Treg and Th17 cells. Mol Med Rep. 2017;15(6):3615-22.

49. Wen $\mathrm{HL}$, Yang G, Dong QR. Ellipticine inhibits the proliferation and induces apoptosis in rheumatoid arthritis fibroblast-like synoviocytes via the STAT3 pathway. Immunopharmacol Immunotoxicol. 2017;39(4):219-24.

50. Zhao YC, Xue CH, Zhang TT, Wang YM. Saponins from Sea Cucumber and Their Biological Activities. J Agric Food Chem. 2018;66(28):7222-37.

51. He Y, Hu Z, Li A, Zhu Z, Yang N, Ying Z, et al. Recent advances in biotransformation of saponins. Molecules. 2019;24(13):1-21.

52. Ma X, Chen G, Wang J, Xu J, Zhao F, Hu M, et al. Pedunculoside attenuates pathological phenotypes of fibroblast-like synoviocytes and protects against collagen-induced arthritis. Scand J Rheumatol. 2019;48(5):383-92.
53. Yu WG, Shen Y, Wu JZ, Gao YB, Zhang LX. Madecassoside impedes invasion of rheumatoid fibroblast-like synoviocyte from adjuvant arthritis rats via inhibition of NF-kB-mediated matrix metalloproteinase-13 expression. Chin J Nat Med. 2018;16(5):330-8. Available from: https://doi.org/10.1016/S1875-53 64(18)30064-5.

54. Kwon OG, Ku SK, An HD, Lee YJ. The effects of platycodin D, a saponin purified from platycodi radix, on collagen-induced DBA/1J mouse rheumatoid arthritis. Evidence-based Complement Altern Med. 2014; 2014:1-16.

55. Guo $Y$, Xing E, Liang $X$, Song H, Dong W. Effects of total saponins from Rhizoma Dioscoreae Nipponicae on expression of vascular endothelial growth factor and angiopoietin-2 and Tie-2 receptors in the synovium of rats with rheumatoid arthritis. J Chinese Med Assoc. 2016;79(5):264-71. Available from: https://doi.org/10.1016/j.jcma.2015.10.012.

56. Liu C, Yang Y, Sun D, Wang C, Wang H, Jia S, et al. Abbreviated title: $4411(16): 1-40$

57. Liu Y, Li M, He Q, Yang X, Ruan F, Sun G. Periploca forrestii saponin ameliorates murine CFA-induced arthritis by suppressing cytokine production. Mediators Inflamm. 2016;2016.

58. Javadi F, Ahmadzadeh A, Eghtesadi S, Aryaeian N, Zabihiyeganeh M, Rahimi Foroushani A, et al. The Effect of Quercetin on Inflammatory Factors and Clinical Symptoms in Women with Rheumatoid Arthritis: A Double-Blind, Randomized Controlled Trial. J Am Coll Nutr. 2017;36(1):9-15.

59. Ahmad S, Alam K, Hossain MM, Fatima M, Firdaus F, Zafeer MF, et al. Antiarthritogenic and cardioprotective action of hesperidin and daidzein in collagen-induced rheumatoid arthritis. Mol Cell Biochem. 2016:423(1-2): $115-27$

60. Jiang $C P$, He X, Yang $X L$, Zhang $S L$, Li H, Song ZJ, et al. Anti-rheumatoid arthritic activity of flavonoids from Daphne genkwa. Phytomedicine. 2014; 21(6):830-7. Available from: https://doi.org/10.1016/.jphymed.2014.01.009.

61. Sun Y wen, Bao Y, Yu H, Chen Q, jing, Lu F, Zhai S, et al. Anti-rheumatoid arthritis effects of flavonoids from Daphne genkwa. Int Immunopharmacol. 2020;83(November 2019):106384. Available from: https://doi.org/10.1016/j. intimp.2020.106384.

62. Chi L, Gao W, Shu X, Lu X. A natural flavonoid glucoside, icariin, regulates th17 and alleviates rheumatoid arthritis in a murine model. Mediators Inflamm. 2014:2014:1-10.

63. Zhai KF, Duan H, Cui CY, Cao YY, Si JL, Yang HJ, et al. Liquiritin from Glycyrrhiza uralensis Attenuating Rheumatoid Arthritis via Reducing Inflammation, Suppressing Angiogenesis, and Inhibiting MAPK Signaling Pathway. J Agric Food Chem. 2019;67(10):2856-64.

64. Wang X, He X, Zhang CF, Guo CR, Wang CZ, Yuan CS. Anti-arthritic effect of berberine on adjuvant-induced rheumatoid arthritis in rats. Biomed Pharmacother. 2017;89:887-93. Available from: https://doi.org/10.1016/j. biopha.2017.02.099.

65. Shan L, Tong L, Hang L, Fan H. Fangchinoline supplementation attenuates inflammatory markers in experimental rheumatoid arthritis-induced rats. Biomed Pharmacother. 2019;111(September 2018):142-50.

66. Liu C, Yang Y, Sun D, Wang C, Wang H, Jia S, et al. Total saponin from Anemone flaccida Fr. Schmidt prevents bone destruction in experimental rheumatoid arthritis via inhibiting osteoclastogenesis. Rejuvenation Res. 2015;18(6):528-42. Available from: https://doi.org/10.1089/rej.2015.1688. Epub 2015 Sep 29

67. Liang XJ, Guo YC, Sun TY, Song HR, Gao YX. Anti-angiogenic effect of total saponins of Rhizoma Dioscorea nipponica on collagen induced-arthritis in rats. Exp Ther Med. 2016;12(4):2155-60.

\section{Publisher's Note}

Springer Nature remains neutral with regard to jurisdictional claims in published maps and institutional affiliations. 